\title{
Plasma polymer film designs through the eyes of ToF-SIMS
}

\author{
Laetitia Bernard ${ }^{\text {a) }}$ \\ Laboratory for Nanoscale Materials Science, Empa, Überlandstrasse 129, 8600 Dübendorf, Switzerland \\ Patrick Rupper \\ Laboratory for Advanced Fibers, Empa, Lerchenfeldstrasse 5, 9014 St. Gallen, Switzerland \\ Greta Faccio \\ Laboratory for Biointerfaces, Empa, Lerchenfeldstrasse 5, 9014 St. Gallen, Switzerland \\ Dirk Hegemann \\ Laboratory for Advanced Fibers, Empa, Lerchenfeldstrasse 5, 9014 St. Gallen, Switzerland \\ Olivier Scholder \\ Laboratory for Nanoscale Materials Science, Empa, Überlandstrasse 129, 8600 Dübendorf, Switzerland \\ Manfred Heuberger \\ Laboratory for Advanced Fibers, Empa, Lerchenfeldstrasse 5, 9014 St. Gallen, Switzerland \\ Katharina Maniura-Weber \\ Laboratory for Biointerfaces, Empa, Lerchenfeldstrasse 5, 9014 St. Gallen, Switzerland \\ Marianne Vandenbossche \\ Laboratory for Advanced Fibers, Empa, Lerchenfeldstrasse 5, 9014 St. Gallen, Switzerland
}

(Received 15 November 2017; accepted 27 February 2018; published 5 April 2018)

Time-of-flight secondary ion mass spectrometry (ToF-SIMS) is increasingly used for the detailed chemical characterization of complex organic materials. Of particular interest in biointerface materials, it provides the accurate molecular information on their surface, a prerequisite for the understanding of subsequent interaction with biomaterials. Plasma polymer films are promising biointerface materials, as tuning the deposition parameters allows the control over film stability and density of surface functional groups. However, the optimization of these film properties not only requires a detailed characterization of the film chemistry, but also that of the deposition mechanisms. Here, ToF-SIMS is used within its different operation modes to investigate those on several plasma polymer film designs. The detailed information on surface molecular chemistry, interface conformation, vertical and lateral chemical and cross-linking gradients is gathered and linked to the underlying deposition mechanisms. In combination with other techniques, the interpretation and understanding of the final functional property of the films in terms of protein adsorption and site-specific binding is achieved. Published by the AVS. https://doi.org/10.1116/1.5016046

\section{INTRODUCTION}

The fast growing interest for plasma polymer films in the biomedical field originates from their solvent-free, environmentally sustainable, and industry transferable deposition methods. ${ }^{1,2}$ Considering also the versatility of the latter in terms of substrate material and three-dimensional (3D) shape, plasma polymer films reveal to be very attractive in numerous applications, such as drug release, ${ }^{3}$ tissue engineering, ${ }^{4}$ cell cultivation, ${ }^{5,6}$ and bio-sensing. ${ }^{7-9}$

The deposition of plasma polymer films is obtained via electrical discharge through a gas, typically an organic precursor such as ethylene, and sometimes complemented with a reactive gas such as $\mathrm{CO}_{2}, \mathrm{NH}_{3}$, or $\mathrm{O}_{2}$, to increase the chemical functionality of the resulting film. ${ }^{10}$ The discharge promotes the formation of reactive species such as ions, electrons, radicals, neutral film-forming species, and also ultraviolet-visible photons. Within the resulting plasma, dissociation,

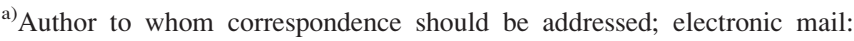
Laetitia.Bernard@empa.ch
}

recombination and diffusion of the reactive and nonreactive species occur, followed by subsequent surface reactions, such as ionic bombardment, diffusion, and eventually deposition of the resulting film-forming species at surfaces. This leads to the formation of a polymer thin film characterized by the presence of reactive chemical groups - the functional groups-at its surface. Tuning the deposition parameters (gas types, relative ratios and flow rates, power input, and deposition time) permits to control the thickness of the film, its cross-linking degree, and the type and density of functional groups at its surface. ${ }^{11}$ A wide diversity of surface properties can be obtained, such as hydrophilicity/-phobicity, ${ }^{12,13}$ antifouling, ${ }^{12}$ or adsorption, ${ }^{14,15}$ to provide the desired functionality to the film.

Besides functionality, a crucial aspect to also consider when designing a plasma polymer film is its structural stability. Typically, such films were found to have a poor stability in water, mainly due to film dissolution. ${ }^{16}$ This a priori represents a strong limitation for most biomedical applications as implying uncertainty about the actual surface composition in biomaterial interaction. Strategies were developed to improve stability via the increase in the cross-linking degree 
of the polymer film, at the cost of the density of functional groups though. ${ }^{11,17}$ Recently, new film designs, based on vertical cross-linking gradients, were proposed to overcome this limitation. ${ }^{18-21}$ Being able to optimize the balance between functionality and stability relies on the ability to accurately characterize both the interplay of the deposition mechanisms and the final chemistry of the resulting film.

One of the most frequently used methods for plasma polymer film chemical characterization is $\mathrm{x}$-ray photoelectron spectroscopy (XPS). ${ }^{22,23}$ With this technique, a precise quantification of elements can be obtained at the surface and near-surface of the film, allowing the assessment of global chemical trends. Static secondary ion mass spectrometry (SIMS) ${ }^{24}$ has also been used, often as a complement to XPS, to provide extreme surface sensitivity $(\approx 1 \mathrm{~nm})$, direct molecular information, and even some structural information, e.g., on the cross-linking degree. ${ }^{25-28}$ Recently, first time-of-flight SIMS (ToF-SIMS) studies were demonstrated to be promising for the in-depth characterization of plasma polymer multilayers or gradients. ${ }^{29}$

Here, amino- and carboxylic acid-based polymers - of general interest for the design of bio-interfaces, ${ }^{30,31}$ are considered. Various film designs including bilayers and microstructured films are presented. With the objective of optimizing both the final stability and functionality of these films for bio-sensing, the detailed analysis of the local molecular chemistry is performed via different operation modes of ToF-SIMS. Surface spectrometry, ultrashallow in-depth profiling, imaging and 3D analysis reveal crucial aspects of the films such as surface molecular chemistry, layers interface position and shape, vertical and lateral chemical and/or crosslinking gradients. In combination with results from other surface characterization techniques, this allows a sound interpretation and understanding of the macroscopic properties of the films and a detailed assessment of their functionality in terms of protein adsorption and site-specific binding.

\section{MATERIALS AND METHODS}

\section{A. Plasma polymer films design and fabrication}

All plasma polymer films presented here were prepared using a symmetric plasma reactor made of two plane disk parallel electrodes $(30 \mathrm{~cm}$ in diameter) separated by a glass ring $(5 \mathrm{~cm}$ in height). The upper electrode (ground electrode) includes a gas showerhead that allows a homogeneous gas mixture flow in the chamber. The gas is pumped away through the lower electrode, which is capacitively coupled to a $13.56 \mathrm{MHz}$ radiofrequency generator. ${ }^{32}$ All depositions were performed at a gas pressure of $10 \mathrm{~Pa}$.

Prior to plasma deposition, silicon wafer substrates were washed with ethanol and then cleaned in Ar plasma ( $\mathrm{Ar}$ $20 \mathrm{sccm}, 50 \mathrm{~W}, 10 \mathrm{~Pa}$, and $10 \mathrm{~min}$ ). Carboxylic acid-based (named "CO-") plasma polymer films with a lateral chemical gradient were obtained using a mixture of $\mathrm{CO}_{2}$ reactive gas and $\mathrm{C}_{2} \mathrm{H}_{4}$ precursor with constant deposition parameters (see Table I), and a $4^{\circ}$-inclined rigid polyethylene terephthalate (PET) plate $\left(5 \times 5 \mathrm{~cm}^{2}\right)$ in contact with the substrate on one end and partially masking the substrate [see Fig. 1(a)]. ${ }^{33}$

Amino-based (named "CN-"), respectively, CO-bilayers were deposited in a one-step process by a fast change of the plasma conditions at a predefined point in time during the deposition to obtain a highly cross-linked polymer base layer, covered by a less cross-linked but more functional top layer. ${ }^{19,21}$ On the one hand, the power was decreased to reduce the ionic bombardment and thus the cross-linking of the top layer polymer. On the other hand, the gas mixture ratio was changed to increase the relative proportion of the reactive gas $\left(\mathrm{NH}_{3}\right.$, respectively, $\left.\mathrm{CO}_{2}\right)$ as compared to the precursor $\left(\mathrm{C}_{2} \mathrm{H}_{4}\right)$ and thus increase the film functionality. $\mathrm{CO} / \mathrm{CN}$ bilayers were prepared in a two-step process, required as two different reactive gases are used. A CN-base layer was first deposited in similar conditions as for the CNbilayer. Then, the gas injection was stopped, the chamber was evacuated, the reactive gas was exchanged from $\mathrm{NH}_{3}$ to $\mathrm{CO}_{2}$, and the gas injection was started again for the deposition of the CO-top layer. ${ }^{34}$

Microstructured films were prepared by first depositing a plain $\mathrm{CN}$-base layer similarly to that of the bilayers, and then by depositing a CO-top layer through a precision plain weave textile mesh (SEFAR PET 1500 36/92-90W PW) with $183 \times 183 \mu \mathrm{m}^{2}$ square openings, and nominal thread diameter of $90 \mu \mathrm{m}$ [see schematics in Fig. 5(c)]..$^{35}$ Table I summarizes the deposition parameters for all films presented here.

TABLE I. Plasma deposition parameters used to prepare the $\mathrm{CN}$ - and CO-polymer layers for all films presented here. Note that in all cases, the layer thickness was calculated based on previously determined deposition rates (see supplementary material, Table S1) (Ref. 59). The parameters for the corresponding reference films can be found in Table S2, supplementary material.

\begin{tabular}{|c|c|c|c|c|c|c|c|}
\hline & & Power input (W) & Reactive gas & Gas flow (sccm) & Precursor & Gas flow (sccm) & Thickness (nm) \\
\hline CO-lateral gradient film & & 50 & $\mathrm{CO}_{2}$ & 8 & $\mathrm{C}_{2} \mathrm{H}_{4}$ & 4 & $0-190$ \\
\hline \multirow[t]{2}{*}{ CN-bilayer } & Base-layer & 70 & $\mathrm{NH}_{3}$ & 4 & $\mathrm{C}_{2} \mathrm{H}_{4}$ & 7 & 15 \\
\hline & Top-layer & 50 & $\mathrm{NH}_{3}$ & 7 & $\mathrm{C}_{2} \mathrm{H}_{4}$ & 7 & 18 \\
\hline \multirow[t]{2}{*}{ CO-bilayers } & Base-layer & 70 & $\mathrm{CO}_{2}$ & 8 & $\mathrm{C}_{2} \mathrm{H}_{4}$ & 4 & 18 \\
\hline & Top-layer & 30 & $\mathrm{CO}_{2}$ & 24 & $\mathrm{C}_{2} \mathrm{H}_{4}$ & 4 & 1,2 \\
\hline \multirow[t]{2}{*}{$\mathrm{CO} / \mathrm{CN}$ bilayers } & Base-layer & 50 & $\mathrm{NH}_{3}$ & 7 & $\mathrm{C}_{2} \mathrm{H}_{4}$ & 7 & 5 \\
\hline & Top-layer & 30 & $\mathrm{CO}_{2}$ & 24 & $\mathrm{C}_{2} \mathrm{H}_{4}$ & 4 & $1,2,3$ \\
\hline \multirow[t]{2}{*}{$\mathrm{CO} / \mathrm{CN}$ microstructured films } & Base-layer & 50 & $\mathrm{NH}_{3}$ & 7 & $\mathrm{C}_{2} \mathrm{H}_{4}$ & 7 & 5 \\
\hline & Top-layer & 30 & $\mathrm{CO}_{2}$ & 24 & $\mathrm{C}_{2} \mathrm{H}_{4}$ & 4 & $5,3^{\mathrm{a}}$ \\
\hline
\end{tabular}

${ }^{\mathrm{a}}$ For the films presented in Figs. 5 and 6, respectively. 

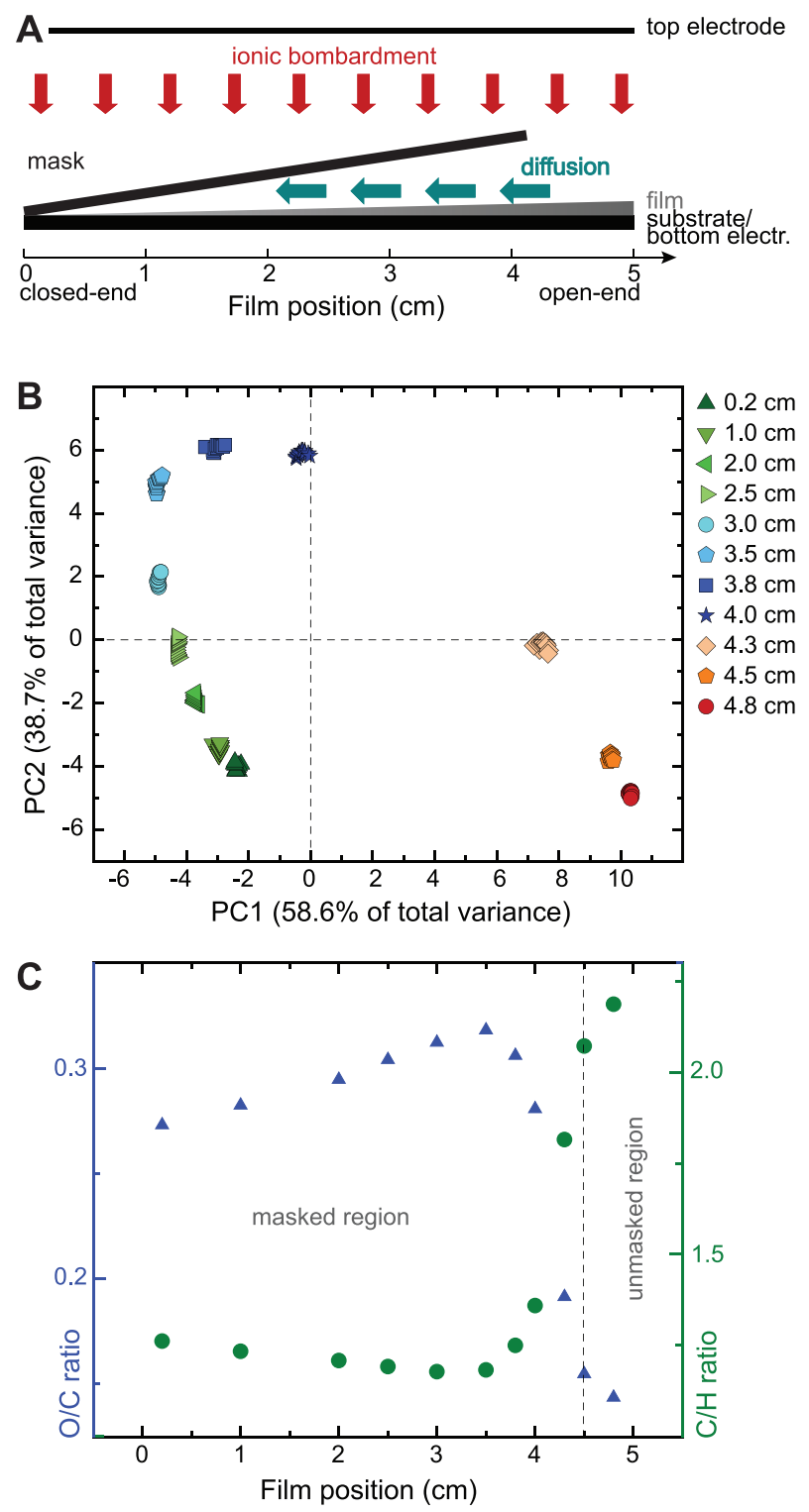

FIG. 1. (a) Schematics of the deposition geometry and expected mechanisms. (b) PC2 vs PC1 score plot calculated from the full ToF-SIMS data set, comprising 12 replicate measurements at each of 11 positions along the film. (c) Evolution of the $\mathrm{O} / \mathrm{C}$ and $\mathrm{C} / \mathrm{H}$ ratios along the film calculated from the direct fragments intensity analysis.

\section{B. Film chemical properties characterization}

XPS measurements were performed with a Scanning XPS Microprobe (PHI VersaProbe II spectrometer, Physical Electronics) using monochromatic $\mathrm{Al} \mathrm{K} \alpha$ radiation $(1486.6 \mathrm{eV})$ and operating at a pressure below $5 \times 10^{-7} \mathrm{~Pa}$. A microfocused x-ray beam with a diameter of $100 \mu \mathrm{m}$ and a $180^{\circ}$ spherical capacitor energy analyzer operated in the fixed analyzer transmission mode were used. High resolution spectra and angle-resolved x-ray photoelectron spectra (ARXPS) were acquired over carbon C1s (energy range: 278 to $298 \mathrm{eV}$ ), oxygen O1s (energy range: 523 to $543 \mathrm{eV}$ ), and $\mathrm{N}$ 1s (energy range: 391 to $411 \mathrm{eV}$ ) at take-off angles of $45^{\circ}$ (XPS) and $15^{\circ}, 30^{\circ}, 45^{\circ}, 60^{\circ}$, and $75^{\circ}$ (ARXPS). The energy step was $0.125 / 0.2 \mathrm{eV}$ and analyzer pass energy
$29.35 / 46.95 \mathrm{eV}$, leading to an energy resolution of $0.7 /$ $0.85 \mathrm{eV}$ for XPS/ARXPS, respectively. Sample charging was compensated using a flux of low energetic electrons $(\approx 1 \mathrm{eV})$ combined with low energy positive $\mathrm{Ar}$ ions $(10 \mathrm{eV})$. Consecutive measurements at the same sample position were performed to ensure that no significant damage occurred during measurements. Intensity determination and curve fitting (least-squares fit routines) were carried out with the software CASAXPS 2.3.16 (Casa Software, Ltd., Teignmouth, UK) using a mixed Gaussian-Lorentzian product function (constant ratio of $70 \%$ Gaussian and 30\% Lorentzian). The positions on the binding energy scale were constraint to within $\pm 0.5 \mathrm{eV}$ of corresponding literature values ${ }^{36}$ and the full width at half maximum values were set equal to each other as customary for the analysis of plasma polymer films. ${ }^{37}$ Atomic concentrations were calculated from XPS peak areas after subtracting a Shirley type background. ${ }^{38}$ Thereby, tabulated sensitivity factors ${ }^{39}$ corrected for the transmission function of the system and spectrometer geometry (asymmetry function) have been used for quantification. The measured amounts are given as normalized atomic concentrations. Relative uncertainties in the concentration determination are estimated to approximately $\pm 10 \%$. The detection limit for light elements $(\mathrm{N}, \mathrm{Si})$ under these experimental conditions is estimated to be $\approx 0.1$ at. $\%$, based on standard procedure. ${ }^{40}$

The ToF-SIMS chemical characterization of all films was performed with a ToF-SIMS.5 instrument (IONTOF, Germany) operating in several configuration modes optimized for spectrometry, depth profiling, imaging and 3D analysis, respectively. All studies were performed with primary bismuth cluster ions at a pressure below $5 \times 10^{-8} \mathrm{mbar}$, and negatively charged secondary ions from mass 1 to 550 $\mathrm{Da}$ were detected in parallel with a sensitivity in the ppm range. Note that the positive secondary ions were not considered here as they carry significantly less useful information in term of oxygen-containing species. Spectrometry was performed to reveal the molecular composition of the topmost surface (first few monolayers) of films using $25 \mathrm{keV} \mathrm{Bi}_{3}^{+}$primary ions in a high mass resolution mode $(M / \Delta M \approx 5000)$. Three to twelve randomly selected areas of $200 \times 200 \mu \mathrm{m}^{2}$ $\left(128 \times 128\right.$ pixels $\left.^{2}\right)$ were investigated to ensure statistically relevant results. For each measurement, a total of 50 scans were acquired, in order to remain below the static limit $\left(<10^{12}\right.$ ions $\left./ \mathrm{cm}^{2}\right)$. Advanced statistical analysis of the data was performed via principle component analysis (PCA) with the software SIMCA 14.1 (MKS Umetrics AB). PCA is a multivariate mathematical method that reduces highdimensional data sets (large number of peaks in large number of spectra) to few orthogonal dimensions only, called "principal components" (PC). ${ }^{41,42}$ This is achieved by extracting from the data set the differences or "variances" between the spectra, and sorting them in term of largest variance (PC1), second largest variance (PC2), etc. Multivariate analysis is particularly suited for the investigation of plasma polymer films, for which only relatively small chemical variations are expected. ${ }^{25,26}$ 
Depth profiling was performed in dual beam mode to track the evolution of the molecular species through the thickness of bilayers and to study the molecular composition of the chemical transition at the two layers interface. To achieve this, a $250 \mathrm{eV} \mathrm{Cs}^{+}$sputtering beam was used in combination with the $\mathrm{Bi}_{3}^{+}$analysis beam to slowly abrade through the bilayers and access the in-depth information. While the analysis areas were limited to $100 \times 100 \mu \mathrm{m}^{2}$, the sputtering was performed on concentric areas of $700 \times 700$ $\mu \mathrm{m}^{2}$ to ensure a homogeneous surface of analysis and a slow abrasion rate. For each analysis, three to four depth profiles were performed at randomly selected areas to insure the measurements reproducibility. Imaging was performed to gather information on the lateral distribution of the surface molecular species for microstructured films. There, a $50 \mathrm{keV}$ $\mathrm{Bi}_{3}^{++}$beam was used in high lateral resolution mode $(\approx 200 \mathrm{~nm})$. A gentle sputtering with a low energy $\mathrm{Cs}^{+}$beam $\left(250 \mathrm{eV}, 1000 \times 1000 \mu \mathrm{m}^{2}\right)$ was simultaneously used to boost the ionization yield in the negative polarity. Secondary ions image data, containing the full compositional spectrum at each pixel, were acquired on randomly selected $500 \times 500$ $\mu \mathrm{m}^{2}$ areas with a $256 \times 256$ pixels $^{2}$ resolution. The $3 \mathrm{D}$ analysis was performed by combining imaging and depth profiling modes, with 120 cycles of successive image acquisition and sputtering. The resulting stack of images was reconstructed into a $3 \mathrm{D}$ volume of $256 \times 256 \times 120$ pixels $^{3}$ or "voxels," containing the full spectral information at each voxel. Note that since the sample topography cannot be addressed by ToF-SIMS, a subsequent topography correction based on the assumption of flat substrate (but neglecting the differences in erosion rates) was performed with an in-house developed Python correction routine. ${ }^{43}$

\section{Film macroscopic properties characterization and performance assessment}

Dynamic water contact angle (WCA) was used to provide information on the relative hydrophilicity of the bilayer films, ${ }^{23}$ using a drop shape analyzer in automatic mode (DSA25 Krüss). The advancing angle was measured for freshly prepared films after 20 min of air storage. A $5 \mu$ drop of water (CHROMASOLV ${ }^{\circledR}$ for HPLC, Sigma Aldrich) was initially deposited onto the surface of the films, with the needle of the analyzer very close to the surface in the middle of the drop. Then the volume of the drop was successively increased to $50 \mu \mathrm{l}$ and decreased to $3 \mu \mathrm{l}$ at a rate of $30 \mu \mathrm{l} /$ min. To ensure measurement reproducibility, several drops on three sample replicates of each type were investigated.

The surface $\zeta$-potential (SZP) was investigated to gain information on the relative charge state of the bilayer films. A Nano SZP (Malvern Instruments) was used, equiped with a ZEN1020 dip cell ${ }^{44}$ and micromer ${ }^{\circledR}$ PEGylated polystyrene monodispersed tracer particles of $1 \mu \mathrm{m}$ diameter (micromod Partikeltechnologie $\mathrm{GmbH}$ ) and $5 \mu \mathrm{g} / \mathrm{ml}$ concentration in phosphate buffer $(p \mathrm{H} 7.00 \pm 0.05)$. The mobility of the tracer particles was measured at different distances from the surface: 125, 250, 375 and $500 \mu \mathrm{m}$. Knowing the intrinsic zeta potential of the particles $(-14 \pm 1 \mathrm{mV})$, the $\zeta$-potential of the films surface could thus be calculated.

Green fluorescent protein (GFP) in its optimized version GFPuv was recombinantly produced ${ }^{45}$ and used as model protein to probe the functionality-the protein adsorption and/or covalent binding - on different film designs. For the study of the $\mathrm{CO} / \mathrm{CN}$ bilayers, a GFPuv carrying a net negative surface charge was used. A $100 \mu \mathrm{l}$ droplet of protein solution $(2 \mathrm{mg} / \mathrm{ml}$ in potassium phosphate buffer of $p \mathrm{H}$ $7.00 \pm 0.05$ ) was deposited for $30 \mathrm{~min}$ on the films at room temperature, in the dark and under humid atmosphere to avoid evaporation. The site-specific covalent binding of GFP on the microstructured films was performed using a tyrosinase enzyme-assisted approach and the Y-tagged version of GFP (Y1-GFPuv). ${ }^{46}$ In contrast to the GFP used for the bilayers study, the latter was further covalently bound to surface amino-groups by the use of tyrosinase. ${ }^{47}$ In this case, a $200 \mu \mathrm{l}$ droplet of protein solution $[2 \mathrm{mg} / \mathrm{ml}$ in potassium phosphate buffer of $p \mathrm{H} 6.8$ supplemented with $0.1 \mathrm{mg} / \mathrm{ml}$ tyrosinase (T3824, Sigma Aldrich)] was deposited on the films for $3 \mathrm{~h}$ at room temperature and under humid atmosphere. In both cases, the films were first immersed in deionized water overnight to neutralize the still-living radicals, ${ }^{48}$ and rinsed in buffer after protein exposure to ensure the full removal of the loosely interacting proteins. All films were finally air-dried.

The adsorption, respectively, binding of GFP was then assessed by fluorescence intensity measurement with a LS Reloaded Microarray Scanner (Tecan, Switzerland) equipped with a $488 \mathrm{~nm}$-laser and a $532 \mathrm{~nm}$ Fluorescein Isothiocyanate filter. Fluorescence intensity values obtained from films exposed to protein-free solutions under identical conditions were used as control. In Fig. 4, the fluorescence intensity signal obtained with the protein-free solution was subtracted from the intensity signal obtained after exposure to the protein (background subtraction). Imaging was performed with a gain of 140 and a spatial resolution of 4-10 $\mu \mathrm{m}$.

\section{RESULTS AND DISCUSSION}

\section{A. Film deposition mechanisms and local properties}

A standard approach to plasma polymer film design is the study of the relationship between "what one tunes"- the deposition parameters, and "what one gets"- the final properties of the film. Although this approach permits to rapidly obtain reasonable results, it is often insufficient to optimize the deposition. This arises from the fact that the deposition results from an interplay of several mechanisms, and this approach only gives access to the convolution of all effects. Considering the mechanisms separately is essential also because they simultaneously influence the same set of film properties, but with different proportions and/or trends. Ionic bombardment and diffusion of film-forming species are two major mechanisms involved in the formation of plasma polymer films. One strategy to deconvolve one from the other is presented in Fig. 1. An inclined mask over a flat substrate is 
used to partially block the ionic bombardment, so that only diffusion is allowed from the open- to the closed-end [Fig. 1(a)]. Beyond the open-end, both mechanisms take place. Chemical and cross-linking lateral gradients between these two regions are thus expected in the resulting polymer film, possibly extending further in the covered region, as observed with other polymer materials. ${ }^{49}$

The chemistry along the film was studied by ToF-SIMS spectrometry at consecutive positions from the closed- to the open-end $(0.2-4.3 \mathrm{~cm})$ and beyond $(4.3-4.8 \mathrm{~cm})$. About 50 polymer characteristic fragments - of form $\mathrm{C}_{x} \mathrm{H}_{y}^{-}$and $\mathrm{C}_{x} \mathrm{H}_{y} \mathrm{O}_{z}^{-}$-were identified and found in mass spectra from all positions. However, only relatively small intensity variations of the otherwise similar peaks could be observed by comparing the spectra of different positions (see supplementary material Fig. S1), ${ }^{59}$ so that a standard analysis could not reveal clear chemical trends. A statistical approach over the totality of spectra and peaks revealed to be necessary.

PCA (see Sec. II) was used to analyze the whole of 12 replicate spectra for each of the 11 sample positions, including all polymer characteristic fragments identified. The two first principal components (PC1 and PC2) were considered, as they together explain $97.3 \%$ of the total variance within the data set and thus contain most of the chemical information. The PC2 versus PC1 scores plot [Fig. 1(b)] reveals a well-defined and regular elliptical pattern that unambiguously differentiates the successive film positions. Note also that all replicates for each position are well grouped with no overlap with data from nearby positions. This analysis reveals a relationship between $\mathrm{PC} 1$ and $\mathrm{PC} 2$ that is not simply linear. Rather, it shows that the evolution of the chemistry along the film cannot reflect a simple gradient between two "quasi" homogeneous phases, and strongly suggests that several distinct processes are involved. The fragments or "loadings" responsible for the variance in PC1 and PC2 exhibit variations in the $\mathrm{O}: \mathrm{C}: \mathrm{H}$ proportions, but do not reveal distinct trends in term of oxygen content or cross-linking degree that could be specifically attributed to PC1 or PC2 (see supplementary material, Tables S3 and S4). ${ }^{59}$ This suggests that the variances revealed by the PCA are distinguishing between some other significant aspects. Considering the elliptical pattern in its ensemble, one sees that data points from positions 4.3 to $4.8 \mathrm{~cm}$ clearly detach from the others and are the only ones to appear in the $\mathrm{PC} 1>0$ pane. As these correspond to the only positions where ionic bombardment was allowed, it strongly suggests that the largest variance$\mathrm{PC} 1$ - distinguishes the ionic bombardment (in $\mathrm{PC} 1>0$ ) from the diffusion mechanism (in $\mathrm{PC} 1<0$ ). Considering the second largest variance-PC2, no such abrupt transition is observed, but a gradual evolution between $\mathrm{PC} 2>0$ to $\mathrm{PC} 2<0$. The loadings reveal that this evolution is characterized by a relative decrease in oxygen content or $\mathrm{O} / \mathrm{C}$ ratioconsidered as representative for the functionality of the film, and an increase in $\mathrm{C} / \mathrm{H}$-related to the cross-linking degree $^{50}$ - while moving down on the PC2 axis (see supplementary material, Table S4). These opposing trends show that the resulting film is not chemically homogeneous along the diffusion path. It suggests that the diffusion mechanism is led by at least two processes that influence both the $\mathrm{O}$ content and the cross-linking.

To verify this, a different data analysis approach that permits to deconvolve these two film properties is needed. Figure 1 (c) presents the overall $\mathrm{O} / \mathrm{C}$ and $\mathrm{C} / \mathrm{H}$ ratios along the sample, directly derived from a classical analysis of the raw spectra. These ratios are calculated by averaging the $\mathrm{O}, \mathrm{C}$ and $\mathrm{H}$ atoms of all fragments, weighted by their respective intensity, for each sample position. The trends along the film of the two ratios are now directly visible. A maximum $\mathrm{O}$ content is observed close to the open-end in the masked region (around $3.5 \mathrm{~cm}$ ), followed by a fast drop into the unmasked region. This drop is clearly explained by the etching induced by the ionic bombardment. ${ }^{51,52}$ On the other hand, a slow decrease is observed in the direction toward the closed-end. A possible explanation is a diffusion-depletion mechanism, which depends on the limited diffusion below the mask and the reactivity-driven depletion of oxygencontaining fragments of the film. This is in contrast to the nonreactive film-forming species such as $\mathrm{C}_{x} \mathrm{H}_{y}$, which have more time to diffuse away until they finally bind to the substrate. Hence, the observed chemical gradient in the masked region can be explained by the separation of the different film-forming species due to reactivity differences. This is in line with the gradual oxygen decrease observed in the PC2 loadings [Fig. 1(b)]. One can thus conclude that PC2 distinguishes between the different reactivity-driven diffusion trends. The $\mathrm{C} / \mathrm{H}$ ratio exhibits opposite trends: with a minimum close to the open-end $(3.5 \mathrm{~cm})$, a fast increase into the unmasked region is observed. This is a direct consequence of ionic bombardment, known to promote cross-linking. ${ }^{11}$ In addition, a slight increase in $\mathrm{C} / \mathrm{H}$ is observed in the direction toward the closed-end. This can be attributed to the decreasing film thickness in this region: ${ }^{33}$ Below a thickness of $\approx 5 \mathrm{~nm}$, ToF-SIMS detects the polymer fragments which are directly attached to the substrate. This is supported by the detection of increasing $\mathrm{SiC}^{-}$intensity in this region (not shown here). These fragments containing less $\mathrm{H}$ end groups due to their attachment, a higher $\mathrm{C} / \mathrm{H}$ ratio is observed.

\section{B. Stability of plasma polymer films}

The above-described ToF-SIMS methodology permits to study in details the film chemical properties and the respective contributions of the different deposition mechanisms. Based on this capability, it is possible to accurately design films with specific macroscopic properties. As both stability in water and high functionality are necessary for bio-sensing applications, a bilayer design with a highly functional layer on the top of a highly cross-linked base layer is beneficial. $^{18,19}$ This is mainly achieved by reducing the ionic bombardment at a given time during deposition. This directly impacts on the further-growing film with reduced crosslinking but also decreased density of functional groups-as observed in Fig. 1(c). To maintain the functionality, the proportion of reactive gas within the initial gas mixture is 
increased. Although this transition in the deposition parameters is performed within few seconds only, the bilayer interface can be broad and possibly include chemical mixing.

Figure 2(a) presents the ToF-SIMS chemical depthprofile of a $\mathrm{CN}$-bilayer with an $18 \mathrm{~nm}$ functional layer on the top of a $15 \mathrm{~nm}$ cross-linked base layer (blue), as compared to a plain highly functional (gray) and plain highly cross-linked (black) reference films. All three films show the same characteristic polymer fragments, but with varying respective intensities. $\mathrm{C}_{4} \mathrm{~N}_{3} \mathrm{H}^{-}$and $\mathrm{Si}^{-}$are displayed to represent the polymer and substrate, respectively. In the plain cross-linked film, $\mathrm{C}_{4} \mathrm{~N}_{3} \mathrm{H}^{-}$is found to be of lower intensity than in the plain functional film, as expected due to the larger reactive gas proportion used for the deposition of the latter. In both cases, the $\mathrm{C}_{4} \mathrm{~N}_{3} \mathrm{H}^{-}$intensity is constant over the full film thickness. The intensity of $\mathrm{C}_{4} \mathrm{~N}_{3} \mathrm{H}^{-}$in the bilayer fits well that of the plain functional film at the surface and in the film depth, until a transition, where it drops down to the level of the plain cross-linked film. This reveals with high precision the position and chemical extent of the bilayer interface. Together with the relative proportions between functional and cross-linked layers of each characteristic fragment, this provides the exact chemical conformation of the bilayer. Note also that the position of the film/substrate interface is different for all three films, in spite of their identical
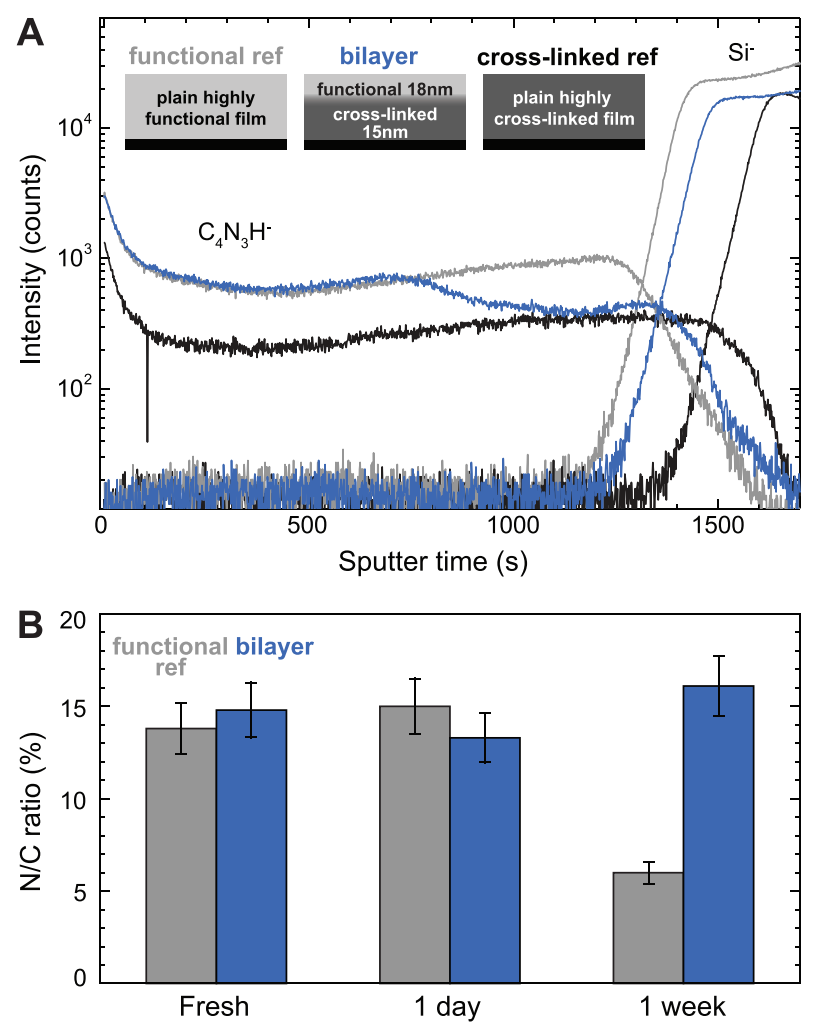

FIG. 2. (a) ToF-SIMS depth profile of the characteristic polymer fragment $\mathrm{C}_{4} \mathrm{~N}_{3} \mathrm{H}^{-}$and substrate fragment $\mathrm{Si}^{-}$for the CN-bilayer (blue), as compared to the plain functional (gray) and cross-linked (black) reference films. Inset: schematics of three films. (b) XPS quantitative assessment of the N/C concentration ratio at the surface of the bilayer (blue) and functional reference (gray), after different aging time in water. The error bars are set to $10 \%$ of the value, to account for instrumental and analysis global error. thickness $(33 \mathrm{~nm})$. This reflects a difference in erosion rate, with the functional film being the fastest and the crosslinked one the slowest to be eroded. The erosion rate being directly linked to the cross-linking degree for similar films (the higher the cross-linking, the lower the erosion rate), this analysis further provides indication on the cross-linking differences within the bilayer.

XPS elemental analysis was performed on an aged bilayer and compared to a plain functional film to verify and quantify their stability. Figure 2(b) presents the N/C ratio as indicator of the film stability after different ageing times in water. While a significant decay of the N/C ratio is observed after one week for the plain functional film, the bilayer shows a preserved chemistry, which in turn is a strong evidence for preserved stability.

For industry-compatible devices though, where the gases amount and deposition time are a cost factor, one would prefer to work with much thinner layers, typically of few nanometers only. In such a case, a progressive chemical gradient is expected, rather than a well-defined interface as shown in Fig. 2. Resolving the shape of the interface in fewnanometers bilayers is very challenging though, as one approaches the depth resolution limit of conventional techniques. Figure 3 presents the study of CO-bilayers with $1 \mathrm{~nm}$ (blue) and $2 \mathrm{~nm}$-thick (green) functional layer on the top of a
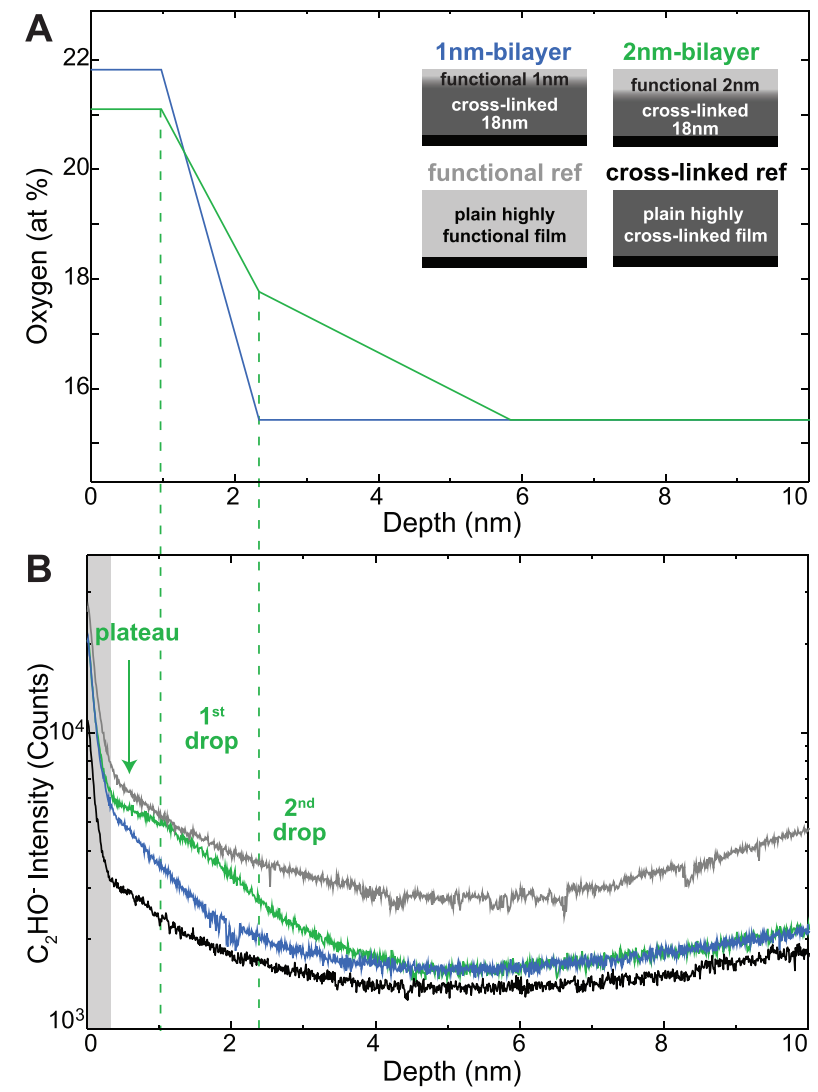

FIG. 3. (a) ARXPS/Cumpson model of the $1 \mathrm{~nm}$ - (blue) and $2 \mathrm{~nm}$ - (green) CO-bilayers interface, after one day aging in air. Inset: schematics of the two bilayers and the two corresponding reference films. (b) ToF-SIMS depth profiles of $\mathrm{C}_{2} \mathrm{HO}^{-}$for the $1 \mathrm{~nm}$ - (blue) and $2 \mathrm{~nm}$-bilayer (green), as compared to the functional (gray) and cross-linked (black) references. 
$18 \mathrm{~nm}$ highly cross-linked base layer (named " $1 \mathrm{~nm}$-bilayer" and " 2 nm-bilayer," respectively). ARXPS data in combination with the Cumpson XPS signal modeling ${ }^{53}$ was used to draw chemical profiles. From that, the accurate oxygen concentration at different depths of the bilayers, and also an approximation of the interface position and shape for both bilayers could be obtained [Fig. 3(a)]. Several other models are available though, that consider different possible shapes of the interface. ${ }^{54}$

Figure 3(b) shows ToF-SIMS depth-profiles of both bilayers, compared to the corresponding plain functional (gray) and highly cross-linked (black) reference films. $\mathrm{C}_{2} \mathrm{HO}^{-}$was selected among the polymer characteristic fragments. Note that the profiles were calibrated in depth based on independent profilometry measurements. Remarkably and in spite of the very small top layer thickness - of the order of the ToF-SIMS depth resolution $(\approx 2 \mathrm{~nm})$, a clear intensity drop from the level of the functional film to that of the crosslinked film are observed for both the $1 \mathrm{~nm}$ - and $2 \mathrm{~nm}$ bilayers. The respective trends are however different. For the $1 \mathrm{~nm}$-bilayer, no initial plateau at the level of the functional film can be observed as the intensity drop immediately follows the transient region of the measurement (grayed zone). Hence, no precise assessment of the interface position can be made. In contrast, the $2 \mathrm{~nm}$-bilayer shows an initial plateau of $\approx 1 \mathrm{~nm}$, followed by a two-step drop spanning over $\approx 2 \mathrm{~nm}$. This not only fully resolves the interface-with its position, extent and shape, but also shows that the composition of the top layer surface remained that of a plain functional film. Note finally the very good match to the ARXPS data (dashed green guidelines). This demonstrates the remarkable consistency and complementarity of ARXPS and ToF-SIMS, with on one hand a precise chemical quantification and on the other hand a direct assessment of the interface position, detailed shape and associated chemical gradient.

\section{Functionality of plasma polymer films}

Figures 2 and 3 showed that the bilayer design can provide increased stability while keeping a preserved top surface chemistry. The latter suggests that the chemical functionality is also preserved, however the presence of the close-by interface could also influence this property. ${ }^{55}$ To investigate this, bilayers designed for protein adsorption were fabricated and studied. The bilayers consist of a highly functional CO-top layer deposited onto a highly cross-linked CN-base layer (two-step deposition), with top layer thickness ranging from $1 \mathrm{~nm}$ to $3 \mathrm{~nm}$ (named $1 \mathrm{~nm}$-bilayer, $2 \mathrm{~nm}$-bilayer and " $3 \mathrm{~nm}$-bilayer," respectively). Surface hydrophilicity and charge state are two major macroscopic properties relevant for the interaction with bio-materials. ${ }^{56}$ Figure 4 presents WCA measurements performed on the three bilayers and the two corresponding references-plain highly functional and plain highly cross-linked films, respectively - to assess the relative hydrophilicity of the bilayers. With smaller advancing angle, the plain functional film (gray) is found to have a better hydrophilicity than the plain
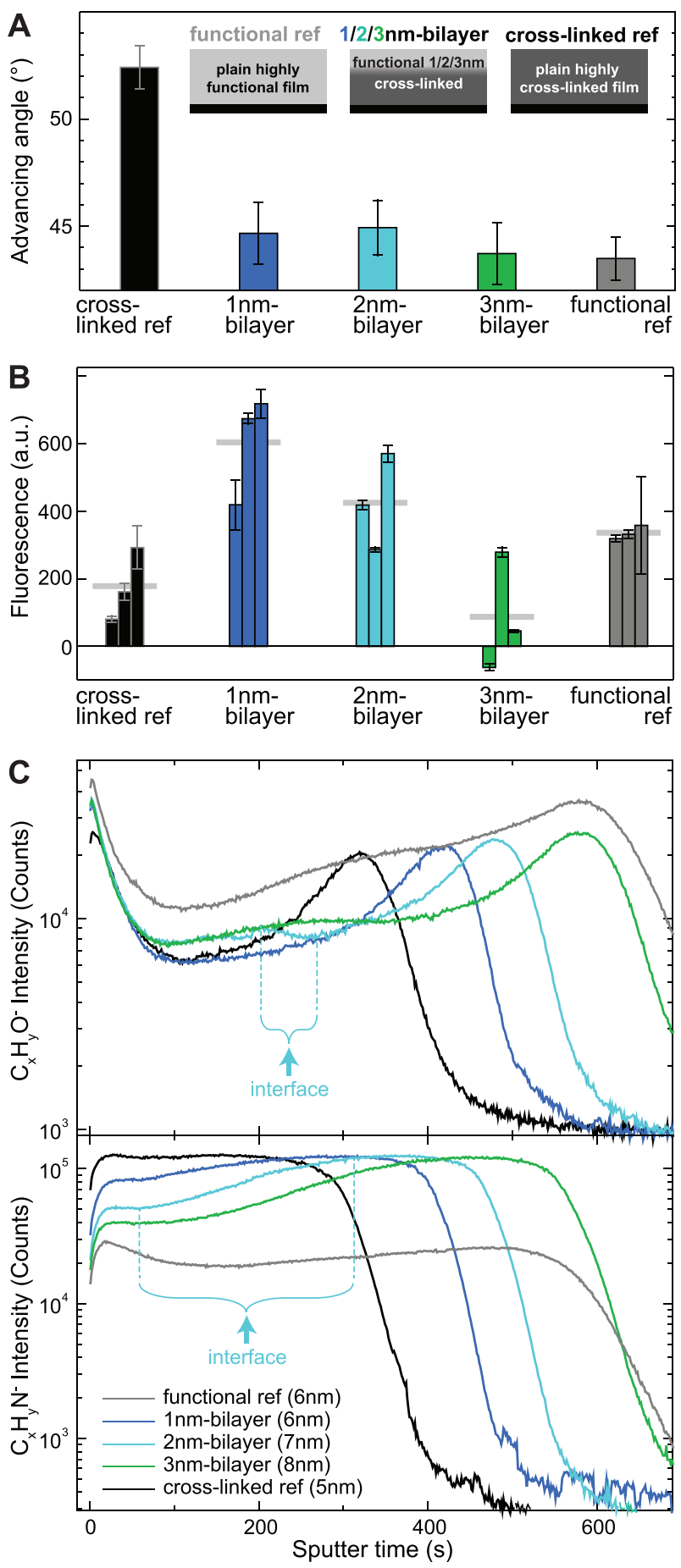

FIG. 4. (a) Dynamic WCA of the $1 \mathrm{~nm}$ - (blue), $2 \mathrm{~nm}-$ (cyan) and $3 \mathrm{~nm}-$ (green) $\mathrm{CO} / \mathrm{CN}$ bilayers, compared to the functional $\mathrm{CO}$ - (gray) and crosslinked $\mathrm{CN}_{-}$(black) reference films (film schematics in the insert). (b) Surface fluorescence intensity of adsorbed GFP on the corresponding films. The gray horizontal bars show the average for each film. (c) ToF-SIMS depth profiles of the corresponding films, with $\mathrm{C}_{x} \mathrm{H}_{y} \mathrm{O}^{-}$(top) and $\mathrm{C}_{x} \mathrm{H}_{y} \mathrm{~N}^{-}$ (bottom), representative for the functional CO- and cross-linked $\mathrm{CN}$ - polymers, respectively.

cross-linked film (black). The three bilayers (blue to green for the $1 \mathrm{~nm}$ - to $3 \mathrm{~nm}$-bilayer, respectively) show advancing angles that are very similar to that of the plain functional film, with only little variations within each other. This 
indicates that the bilayers have similar hydrophilicity properties than the plain functional film, with no or little influence of the top layer thickness. $\zeta$-potential measurements were performed to assess possible differences in the surface charge state of the bilayers in water. $\zeta$-potentials for the plain functional and cross-linked reference films were found to be $-48 \pm 2$ and $-13 \pm 7 \mathrm{mV}$, respectively. The $\zeta$-potentials of the three bilayers were found to be $-46 \pm 1,-50 \pm 3$ and $-50 \pm 9 \mathrm{mV}$ for the 1 - to $3 \mathrm{~nm}$-bilayer, respectively, i.e., very similar to that of the plain functional film. Together with the WCA results, this strongly suggests that the functionality of the bilayers is similar to that of the plain functional film.

In bio-sensing applications, the adsorption of protein is related to the surface chemical functionality. In this context, the direct adsorption of GFP on the bilayers was assessed. Figure 4(b) shows the fluorescence intensity-as an indication for the quantity of adsorbed proteins at the surface-for three replicates of each of the five films. In contrast to the WCA and $\zeta$-potential measurements, the fluorescence intensities for the bilayers are dissimilar to that of the plain functional film: the 1 - and 2 nm-bilayers show significantly larger intensities. The $3 \mathrm{~nm}$-bilayer shows a reduced protein adsorption. Note however that the apparently negative intensity (background corrected) observed for one of the replicates suggests occurrence of a process that has reduced the background intensity (e.g., degradation and/or restructuring).

To shed light on the differing results obtained with WCA and $\zeta$-potential measurements on the one hand and protein adsorption on the other hand, local investigation of the surface and near-surface chemistry was performed by ToFSIMS. Figure 4(c) shows $\mathrm{C}_{x} \mathrm{H}_{y} \mathrm{O}^{-}$(top) and $\mathrm{C}_{x} \mathrm{H}_{y} \mathrm{~N}^{-}$(bottom) depth profiles of all films, as representative for the functional CO-top layer and cross-linked CN-base layer, respectively, (see fragments sums in supplementary material, Table S5). Besides the signs of surface oxidation (increased O-content at the surface) and matrix effect at the film/substrate interface (intensity overshoot at the film/substrate interface), the $\mathrm{C}_{x} \mathrm{H}_{y} \mathrm{O}^{-}$profiles provide two pieces of information. First, the intensities of all bilayers at the surface stand in-between those of the plain functional and cross-linked reference films. This suggests that none of them have the plain COfunctional film chemistry at their surface. Second, a small but clear intensity step at about half-depth is visible for the 2 nm-bilayer (see arrow). This clearly corresponds to the interface between the two layers. Note that for the $3 \mathrm{~nm}$ bilayer, no drop but a plateau is visible, due to the overlap with the matrix effect intensity overshoot. No interface feature is visible in the $1 \mathrm{~nm}$-bilayer, as probably hindered from both sides by the surface oxidation and matrix effect, respectively. The $\mathrm{C}_{x} \mathrm{H}_{y} \mathrm{~N}^{-}$profiles first show that all bilayers contain $\mathrm{C}_{x} \mathrm{H}_{y} \mathrm{~N}^{-}$fragments already at the top surface, confirming that none of the bilayers have the plain CO-functional film composition at the top surface. Second, no sharp interface can be observed, but rather a smooth intensity evolution from the initial to the cross-linked intensity levels. This demonstrates that a significant mixing exists within the bilayers, with a chemical gradient that spans over approximately half of the full thickness (see arrow). Interestingly, this gradual interface for $\mathrm{C}_{x} \mathrm{H}_{y} \mathrm{~N}^{-}$is very different from the comparatively sharper interface of $\mathrm{C}_{x} \mathrm{H}_{y} \mathrm{O}^{-}$on the 2 nm-bilayer. This asymmetric behavior can be explained by the effect of ionic bombardment during the second layer deposition. Results from Fig. 1(c) showed that ionic bombardment induces etching of the underlying material. Here, the base layer being made of $\mathrm{CN}$-polymer, nitrogen-containing fragments are released in the plasma, react with the CO-film-forming species, and are ultimately redeposited within the top layer. The resulting chemical gradient is likely to have a strong influence on the protein adsorption, as previously observed with albumin proteins. ${ }^{55}$ The $\mathrm{N}$-enrichment of the functional CO-top layer could also contribute to the larger protein adsorption, as nitrogen is known to also allow the anchoring of biomaterials such as proteins and cells. ${ }^{30}$ This confirms that biomaterial interaction at plasma-modified surfaces also involves the near-surface region extending a few nanometers below the outermost surface.

The ultimate goal is to develop microfabricated biosensing devices with multicompounds selective adsorption/ binding at specific locations. One way to design this is the deposition of one or more polymers through microstructured masks. ${ }^{57,58}$ Here, a plain functional CN-layer was first deposited, followed by a partially masking CO-top layer deposited through a textile mesh mask, resulting in a $\mathrm{CO} / \mathrm{CN}$ microstructured film. Figure 5(a) presents ToF-SIMS chemical imaging of this film. $\mathrm{C}_{x} \mathrm{~N}_{y}^{-}$(top-left) and $\mathrm{C}_{x}^{-}$(top-right) fragments reveal the resulting microstructured film with the CN- "grid" area and the CO- "square" areas, respectively (see fragments sums in supplementary material, Table S6). Note that although $\mathrm{C}_{x}^{-}$fragments were expected to be found in both layers, they appear to predominantly originate from the CO-top layer. In addition to these fragments, unexpected oxygen-containing fragments were specifically found on the masked "bars" of the grid area, of types $\mathrm{C}_{x} \mathrm{H}_{y} \mathrm{O}_{z}^{-}$and $\mathrm{CH}_{x} \mathrm{NO}^{-}$[Fig. 5(a) middle-left and -right, respectively]. Accounting for the 3D structure of the textile mesh-involving up/down weaving, it is likely that only the "crossings" were fully in contact with the substrate during the top layer deposition, so that diffusion process of O-containing filmforming species could take place under the bars [see Fig. $5(c)]$. Note that the alternatively vertical/horizontal diamondlike shape of the crossings (dashed box on the $\mathrm{C}_{x} \mathrm{H}_{y} \mathrm{O}_{z}^{-}$ image) also originates from the up/down weaving of the mesh [dashed box in Fig. 5(c)]. Another interesting observation resides in the intensity of the $\mathrm{C}_{x} \mathrm{H}_{y} \mathrm{O}_{z}^{-}$fragments. Although the latter are characteristic for the top layer polymer, their intensity is actually much larger on the grid bars than on the square areas. This can be attributed to the $\mathrm{O}$ etching associated with ionic bombardment, as revealed in Fig. 1(c), taking place exclusively on the square areas. In contrast, $\mathrm{CH}_{x} \mathrm{NO}^{-}$fragments cannot originate from the direct diffusion of film-forming species during the top layer deposition as those are $\mathrm{N}$-free. They do not originate from etching and subsequent redeposition of nitrogen-containing 

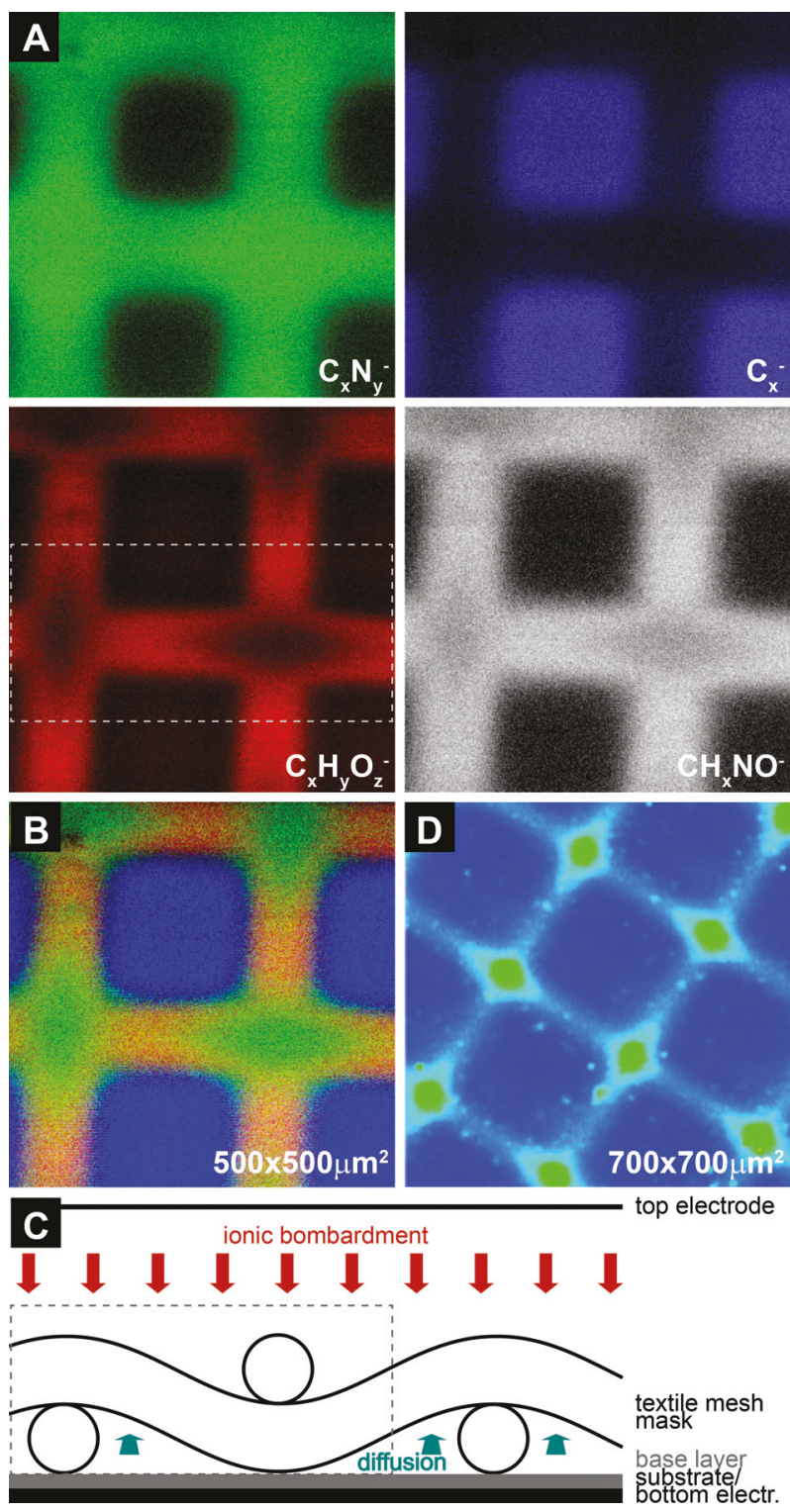

FIg. 5. (a) ToF-SIMS chemical images of the main molecular fragments composing the microstructured film: $\mathrm{C}_{x} \mathrm{~N}_{y}^{-}, \mathrm{C}_{x}^{-}, \mathrm{C}_{x} \mathrm{H}_{y} \mathrm{O}_{z}^{-}$and $\mathrm{CH}_{x} \mathrm{NO}^{-}$. (b) Overlay of the ToF-SIMS chemical images, with $\mathrm{C}_{x} \mathrm{~N}_{y}^{-}$in green, $\mathrm{C}_{x}^{-}$in blue and $\mathrm{C}_{x} \mathrm{H}_{y} \mathrm{O}_{z}^{-}$in red. (c) Schematics of the deposition geometry and mechanisms. The dashed box corresponds to the configuration of the mesh at the imaging position (a). (d) Microarray scanner image of the microstructured film after exposure to GFP, with blue and green representing low and large fluorescence intensity, respectively.

fragments as observed in Fig. 4 because no ionic bombardment takes place under the mesh. Hence, one has to conclude that oxidation of the $\mathrm{CN}$-layer surface occurred due to its interaction with the incoming diffusing O-containing filmforming species.

The resulting chemical map, consequently very different than expected, is displayed as an overlay of the different chemical species in Fig. 5(b). Instead of a two-components microstructure with a $\mathrm{CN}$ - grid and $\mathrm{CO}$ - squares, the such-fabricated microstructured film comprises three components: $\mathrm{CN}$ - grid crossings (green), CO- squares, and CO- grid bars with increased O-content (red). The site-specific tyrosinase-assisted binding of GFP on such microstructured films was then investigated. Figure 5(d) shows the microstructured film after exposure to a GFP, designed in the presence of tyrosinase to covalently bind to the surface amino-groups (see Sec. II). As expected, the GFP specifically binds to the $\mathrm{CN}$-polymer, i.e., at the crossings. No or comparatively negligible adsorption is observed on the squares. However, although significantly lower than on the crossings, some GFP are also observed on the grid bars. This could be explained by the influence of the underneath CN-layer, assuming that the additional O-containing layer on the grid bars is very thin.

To verify this assumption, a 3D ToF-SIMS chemical analysis was performed. Figure 6(a) displays cross-sections (extracted from the $3 \mathrm{D}$ data) of the most representative fragments, and the overlay of $\mathrm{C}_{3} \mathrm{~N}^{-}+\mathrm{C}_{5} \mathrm{~N}^{-}$(green), $\mathrm{C}_{6}^{-}$(blue) and $\mathrm{C}_{2} \mathrm{H}_{3} \mathrm{O}^{-}+\mathrm{C}_{3} \mathrm{H}_{3} \mathrm{O}^{-}+\mathrm{C}_{2} \mathrm{O}^{-}$(red). Note that because the film is not flat ( $\approx 3 \mathrm{~nm}$-high squares), a topography correction was performed to obtain a more realistic rendering of its 3D chemical structure (see details in Sec. II). From this, the top surface O-containing layer on the grid bars comprising $\mathrm{C}_{x} \mathrm{H}_{y} \mathrm{O}_{z}^{-}$and $\mathrm{CH}_{x} \mathrm{NO}^{-}$can be estimated to be $\ll 1 \mathrm{~nm}$, according to the $\approx 8 \mathrm{~nm}$ thickness of the full microstructured film. This is a strong evidence that this O-containing layer is not continuous and that $\mathrm{CN}$-polymer sites are partly available for protein covalent binding. In turn, this explains the reduced but not suppressed protein amount on the grid bars as observed in Fig. 5(c). The TOF-SIMS chemical crosssections also reveal the presence of $\mathrm{O}$-containing species at the film/substrate interface, such as $\mathrm{CNO}^{-}$and $\mathrm{C}_{2} \mathrm{O}^{-}$. In contrast to those of the top surface, they do not contain hydrogen atoms. One can conclude that they are oxidative products that formed during the first polymer layer deposition. This may happen by direct interaction of the O-free CN-filmforming species with the ${ }_{n o x} \mathrm{SiO}_{2}$ surface, and/or by recombination in the plasma phase of released oxygen (due to ionic bombardment) and redeposition of the newly formed Ocontaining species. Note also that the interface between the CN-base and CO-top layers is not sharp but more resembles to a smooth gradient. This is due to the release, recombination and redeposition of nitrogen in the CO-plasma, as already observed in the case of Fig. 4.

Finally, Fig. 6(b) shows the full 3D chemical map of the microstructured film. There, the detailed three-dimensional morphological and chemical conformation of the microstructured film is revealed, with unprecedented information on the molecular composition of the two polymer layers, lateral gradient across the structures, vertical gradients across the bilayer and O-content at the film surface and film/substrate interface.

\section{CONCLUSION}

ToF-SIMS is used here to perform a detailed molecular, chemical and structural characterization of the surface and subsurface of different plasma polymer film designs. This approach revealed to be very useful for the understanding of 

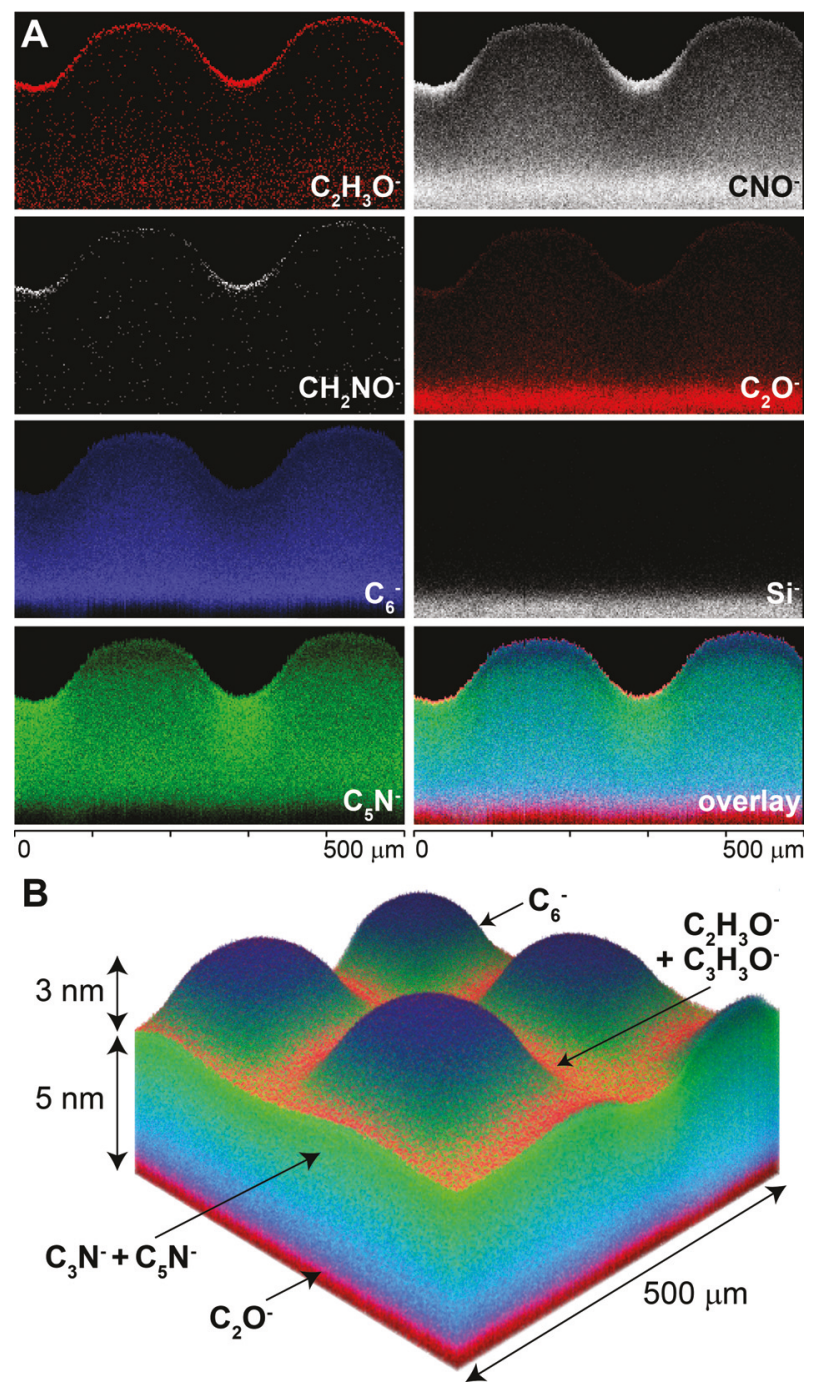

FIG. 6. ToF-SIMS 3D chemical analysis of a microstructured film. (a) Crosssectional maps of the main molecular fragments composing the film, from top surface to substrate (incl.): $\mathrm{C}_{2} \mathrm{H}_{3} \mathrm{O}^{-}, \mathrm{CH}_{2} \mathrm{NO}^{-}, \mathrm{C}_{6}^{-}, \mathrm{C}_{5} \mathrm{~N}^{-}, \mathrm{CNO}^{-}, \mathrm{C}_{2} \mathrm{O}^{-}$ and $\mathrm{Si}^{-}$. Note that the $3 \mathrm{D}$ chemical data was corrected according to the sample topography. (b) 3D chemical map of the film, built by the overlay of the characteristic fragments: $\mathrm{C}_{3} \mathrm{~N}^{-}+\mathrm{C}_{5} \mathrm{~N}^{-}$in green, $\mathrm{C}_{6}^{-}$in blue and $\mathrm{C}_{2} \mathrm{H}_{3} \mathrm{O}^{-}$ $+\mathrm{C}_{3} \mathrm{H}_{3} \mathrm{O}^{-}+\mathrm{C}_{2} \mathrm{O}^{-}$in red.

films macroscopic properties such as their stability and functionality.

While spectrometry with subsequent advanced data analysis permitted to reveal the local chemical and cross-linking lateral gradients, low-energy ultrashallow depth profiling allowed the assessment of buried interfaces between consecutive layers as thin as one to few nanometers only. Depending on the deposition parameters, transitions form sharp interfaces $(<2 \mathrm{~nm})$ to vertical chemical gradients of several nanometers could be demonstrated in bilayers. Imaging and 3D chemical analysis provided a high-resolution molecular 3D mapping of microstructured films. The unprecedented information gained on the actual chemistry of the films-highly nonhomogeneous and significantly different from what was expected, revealed to be essential, in combination with the findings obtained with other techniques, for the interpretation of site-specific protein binding results. Beyond the characterization of the local chemical properties, the different mechanisms involved in the film deposition - including ionic bombardment and reactivitydriven film-forming species diffusion, were identified and distinguished from each other within a dedicated experimental setup. Their competing effects on the film local properties could be deconvolved. This information constitutes the link between the deposition parameters and the resulting film surface properties, and as such, is essential for the sound understanding of the whole process and for an accurate control over the film design.

More generally, this overview study of the main critical aspects of plasma polymer films-stability and functionality-reveals the strength and versatility of the ToF-SIMS technique and establishes it as a powerful complementary method to characterize those films. A more systematic use of ToF-SIMS in the future is foreseen to become a strong asset for the further development of new plasma polymer film designs.

\section{ACKNOWLEDGMENTS}

Coauthors Dirk Hegemann and Marianne Vandenbossche gratefully acknowledge the Swiss National Science foundation (SNSF, Bern) for funding this study under Grant No. IZ73Z0-152661 (SCOPES).

${ }^{1}$ R. Förch, Z. Zhang, and W. Knoll, Plasma Processes Polym. 2, 351 (2005).

${ }^{2}$ K. S. Siow, L. Britcher, S. Kumar, and H. J. Griesser, Plasma Processes Polym. 3, 392 (2006).

${ }^{3}$ S.-W. Myung, S.-C. Jung, and B.-H. Kim, Thin Solid Films 584, 13 (2015).

${ }^{4}$ J. Jagur-Grodzinski, Polym. Adv. Technol. 17, 395 (2006).

${ }^{5}$ M. Kumar, J. X. Piao, S. B. Jin, J. H. Lee, S. Tajima, M. Hori, and J. G. Han, Arch. Biochem. Biophys. 605, 41 (2016).

${ }^{6}$ A. Javid, M. Kumar, L. Wen, S. Yoon, S. B. Jin, J. H. Lee, and J. G. Han, Mater. Des. 92, 405 (2016).

${ }^{7}$ H. Muguruma, A. Hiratsuka, and I. Karube, Anal. Chem. 72, 2671 (2000).

${ }^{8}$ H. Wang, C. Wang, C. Lei, Z. Wu, G. Shen, and R. Yu, Anal. Bioanal. Chem. 377, 632 (2003).

${ }^{9}$ E. Makhneva, A. Manakhov, P. Skládal, and L. Zajíčková, Surf. Coat. Technol. 290, 116 (2016).

${ }^{10}$ H. Biederman, Plasma Polymer Films (Imperial College, London, 2004).

${ }^{11}$ D. Hegemann, E. Körner, N. Blanchard, M. Drabik, and S. Guimond, Appl. Phys. Lett. 101, 211603 (2012).

${ }^{12}$ D. S. Wavhal and E. R. Fisher, J. Membr. Sci. 209, 255 (2002).

${ }^{13}$ D. Hegemann, H. Brunner, and C. Oehr, Plasmas Polym. 6, 221 (2001).

${ }^{14}$ D. Hegemann, H. Brunner, and C. Oehr, Nucl. Instrum. Methods Phys. Res., Sect. B 208, 281 (2003).

${ }^{15}$ N. Graupner, K. Albrecht, D. Hegemann, and J. Müssig, J. Appl. Polym. Sci. 128, 4378 (2013).

${ }^{16}$ A. Manakhov, L. Zajiččová, M. Eliáš, J. Čechal, J. Polčák, J. Hnilica, Š. Bittnerová, and D. Nečas, Plasma Processes Polym. 11, 532 (2014).

${ }^{17}$ S. Swaraj, U. Oran, A. Lippitz, J. F. Friedrich, and W. E. S. Unger, Plasma Processes Polym. 2, 572 (2005).

${ }^{18}$ L. Li et al., Plasma Processes Polym. 6, 615 (2009).

${ }^{19}$ D. Hegemann, E. Lorusso, M.-I. Butron-Garcia, E. N. Blanchard, P. Rupper, P. Favia, M. Heuberger, and M. Vandenbossche, Langmuir 32, 651 (2016)

${ }^{20} \mathrm{P}$. Rupper, M. Vandenbossche, L. Bernard, D. Hegemann, and M. Heuberger, Langmuir 33, 2340 (2017).

${ }^{21}$ J. Dorst, M. Vandenbossche, M. Amberg, L. Bernard, P. Rupper, and D. Hegemann, Langmuir 33, 10736 (2017). 
${ }^{22}$ T. R. Gengenbach, R. C. Chatelier, and H. J. Griesser, Surf. Interface Anal. 24, 271 (1996).

${ }^{23}$ N. Vandencasteele and F. Reniers, J. Electron Spectrosc. Related Phenom. 178-179, 394 (2010).

${ }^{24}$ TOF-SIMS: Surface Analysis by Mass Spectrometry, edited by J. C. Vickerman and D. Briggs (IM Publication and Surface Spectra, Chichester/Manchester, UK, 2001).

${ }^{25}$ A. Chilkoti, B. D. Ratner, and D. Briggs, Anal. Chem. 65, 1736 (1993).

${ }^{26}$ E. E. Johnston and B. D. Ratner, J. Electron Spectrosc. Relat. Phenom. 81, 303 (1996).

${ }^{27}$ S. Fraser, R. D. Short, D. Barton, and J. W. Bradley, J. Phys. Chem. B 106, 5596 (2002).

${ }^{28}$ S. Ligot, F. Renaux, L. Denis, D. Cossement, N. Nuns, P. Dubois, and R. Snyders, Plasma Processes Polym. 10, 999 (2013).

${ }^{29}$ A. Delcorte, V. Cristaudo, M. Zarshenas, D. Merche, F. Reniers, and P. Bertrand, Plasma Processes Polym. 12, 905 (2015).

${ }^{30}$ Y.-C. Lin and M.-J. Wang, Jpn. J. Appl. Phys., Part 1 55, 01 AA04 (2016).

${ }^{31}$ A. G. Guex, F. M. Kocher, G. Fortunato, E. Körner, D. Hegemann, T. P. Carrel, H. T. Tevaearai, and M. N. Giraud, Acta Biomater. 8, 1481 (2012).

${ }^{32}$ D. Hegemann, M. Michlicek, N. Blanchard, U. Schütz, D. Lohmann, M. Vandenbossche, L. Zajickova, and M. Drabik, Plasma Processes Polym. 13, 279 (2016).

${ }^{33}$ M. Vandenbossche, L. Petit, J. Mathon-Lagresle, F. Spano, P. Rupper, L. Bernard, and D. Hegemann, "Formation of lateral chemical gradients in plasma polymer films shielded by an inclined mask," Plasma Processes Polym. (published online).

${ }^{34}$ M. Vandenbossche, M.-I. Butron Garcia, U. Schütz, P. Rupper, M. Amberg, and D. Hegemann, Plasma Chem. Plasma Process. 36, 667 (2016).

${ }^{35}$ M. Vandenbossche, L. Bernard, P. Rupper, K. Maniura-Weber, M. Heuberger, G. Faccio, and D. Hegemann, Mater. Des. 114, 123 (2017).

${ }^{36} \mathrm{G}$. Beamson and D. Briggs, High Resolution XPS of Organic Polymers (Wiley, Chichester, 1992).

${ }^{37}$ P.-L. Girard-Lauriault, W. E. S. Unger, P. M. Dietrich, and A. Holländer, Plasma Processes Polym. 12, 953 (2015).

${ }^{38}$ D. A. Shirley, Phys. Rev. B 5, 4709 (1972).
${ }^{39}$ J. F. Moulder, W. F. Stickle, P. E. Sobol, and K. D. Bomben, Handbook of $X$-Ray Photoelectron Spectroscopy (Physical Electronics, Inc., Eden Prairie, MN, 1995).

${ }^{40}$ A. G. Shard, Surf. Interface Anal. 46, 175 (2014).

${ }^{41}$ J. L. S. Lee and I. S. Gilmore, "The application of multivariate data analysis techniques," in Surface Analysis in Surface Analysis-The Principal Techniques, 2nd ed. (Wiley, Manchester, UK, 2009).

${ }^{42}$ D. J. Graham, Appl. Surf. Sci. 252, 6860 (2006).

${ }^{43}$ O. Scholder, A Python Library for Advanced Data Analysis of ToF-SIMS and SPM Data (Zenodo - CERN, Geneve, CH, 2017).

${ }^{44}$ J. C. Corbett, F. McNeil-Watson, R. O. Jack, and M. Howarth, Colloids Surf. A 396, 169 (2012).

${ }^{45}$ T. Heck, P. H. Pham, F. Hammes, L. Thöny-Meyer, and M. Richter, Bioconjugate Chem. 25, 1492 (2014).

${ }^{46}$ T. Heck, P.-H. Pham, A. Yerlikaya, L. Thöny-Meyer, and M. Richter, Catal. Sci. Technol. 4, 2946 (2014).

${ }^{47}$ G. Faccio, S. Senkalla, L. Thöny-Meyer, and M. Richter, RSC Adv. 5, 22319 (2015).

${ }^{48}$ A. Fahmy, A. Schönhals, and J. Friedrich, J. Phys. Chem. B 117, 10603 (2013).

${ }^{49}$ D. Mangindaan, C. C. Kuo, S. Y. Lin, and M. J. Wang, Plasma Processes Polym. 9, 808 (2012).

${ }^{50}$ D. Cossement, F. Renaux, D. Thiry, S. Ligot, R. Francq, and R. Snyders, Appl. Surf. Sci. 355, 842 (2015).

${ }^{51}$ L. Martinu and D. Poitras, J. Vac. Sci. Technol., A 18, 2619 (2000).

${ }^{52}$ D. Thiry, S. Konstantinidis, J. Cornil, and R. Snyders, Thin Solid Films 606, 19 (2016).

${ }^{53}$ P. J. Cumpson, J. Electron Spectrosc. Relat. Phenom. 73, 25 (1995).

${ }^{54}$ R. W. Paynter, Surf. Interface Anal. 33, 14 (2002).

${ }^{55}$ D. Hegemann, N. E. Blanchard, and M. Heuberger, Plasma Processes Polym. 13, 494 (2016).

${ }^{56}$ D. R. Lu and K. Park, J. Colloid Interface Sci. 144, 271 (1991).

${ }^{57}$ E. Sardella, P. Favia, R. Gristina, M. Nardulli, and R. D'Agostino, Plasma Processes Polym. 3, 456 (2006).

${ }^{58}$ A. George, T. M. Stawski, S. Unnikrishnan, S. A. Veldhuis, and J. E. ten Elshof, J. Mater. Chem. 22, 328 (2012).

${ }^{59}$ See supplementary material at https://doi.org/10.1116/1.5016046 for details on the deposition parameters, mass spectra and characteristic fragments. 